\section{Bücher, die bei uns eingegangen sind}

Adler, Heidrun/Röttger, Kati (Hrsg.) (1998): Geschlechter/-Performance - Pathos - Politik. Das postkoloniale Theater lateinmerikanischer Autorinnen. Theater in Lateinamerika, Bd. 1. Frankfurt/M., Vervuert, 246 S., DM 48.-.

Adler, Heidrun/Röttger, Kati (Hrsg.) (1998): Theaterstücke lateinamerikanischer Autorinnen. Theater in Lateinamerika, Bd. 2, Frankfurt/M., Vervuert, 438 S., DM 48.-.

Andresen, Sabine/Baader, Meike Sophia (1998): Wege aus dem Jahrhundert des Kindes.Tradition und Utopie bei Ellen Key. Neuwied, Luchterhand, 148 S., DM 29,80.-.

Bereswill, Mechthild/Wagner, Leonie (Hrsg.) (1998): Bürgerliche Frauenbewegung und Antisemitismus. Tübingen, edition diskord, 125 S., DM 28.-.

Caduff, Corinna (1998): »dadim dadam « - Figuren der Musik in der Literatur Ingeborg Bachmanns. Literatur - Kultur Geschlecht, Große Reihe, Bd. 12, Köln. Böhlau, 259 S., DM 48.-.

Dölling, Irene/Krais, Beate (Hrsg.) (1998): Ein alltägliches Spiel. Geschlechterkonstruktion in der sozialen Praxis. Gender Studies, Frankfurt/M., Suhrkamp, 333 S., DM 24,80.-.

Frackowiak, Ute (Hrsg.) (1998): Ein Raum zum Schreiben. Schreibende Frauen in Spanien vom 16. bis ins 20. Jahrhundert. Berlin, edition tranvia, 220 S., DM 36.-.

Gehmacher, Johanna (1998): , Völkische Frauenbewegung ‘. Deutschnationale und nationalsozialistische Geschlechterpolitik in Österreich. Wien, Döcker, 394 S., DM 54.-.

Hagemann, Karen/Pröve, Ralf (Hrsg.) (1998): Soldatenfrauen und Nationalkrieger. Militär, Krieg und Geschlechterordnung im historischen Wandel. Geschichte und Geschlechter, Bd. 36, Frankfurt/M., Campus, 368 S., DM 78.-.

Hennessy, Rosemary/Ingraham, Chrys (Hrsg.) (1998): Materialist Feminism. A Reader in Class, Difference, and Women's Lives. London/New York, Routledge, 430 S., L 16,99 (Pb.).

Knesebeck, Alexandra von dem (1998): Käthe Kollwitz. Die prägenden Jahre. Studien zur internationalen Architektur und Kunstgeschichte 6, Petersberg, Michael Imhof Verlag, 264 S., DM 98,-

Lowien, Gertraude (1998): Bilder vom Alltag italienischer Frauen. Erzählte Lebensgeschichte - gesellschaftliche Verhältnisse. Beiträge zur interkulturellen Diskussion, Bd. 7, Münster, LIT, 376 S., DM 48,80.

Medick, Hans/Trepp, Anne-Charlott (Hrsg.) (1998): Geschlechtergeschichte und Allgemeine Geschichte. Herausforderungen und Perspektiven. Göttinger Gespräche zur Geschichtswissenschaft, Bd. 5, Göttingen, Wallstein, 240 S., DM 28. $\rightarrow$.

Regenhard, Ulla (Hrsg.) (1998): Die männliche Wirtschaft. Berlin, edition sigma, rainer bohn verlag, $276 \mathrm{~S}$., DM 29,80.-.

Weckel, Ulrike (1998): Zwischen Häuslichkeit und Öffentlichkeit. Die ersten deutschen Frauenzeitschriften im späten 18. Jahrhundert und ihr Publikum. Studien und Texte zur Sozialgeschichte der Literatur, Bd. 61, Tübingen, Niemeyer, 691 S., DM 192.-. 